\title{
Berichtigungen.
}

Herr von Ott erweist mir eine unverdiente Ehre, indem er auf S. 132 dieses Archivs, Bd. XXVII, schreibt: „Die vor kurzem veröffentlichten Untersuchungen von Runge in Dorpat, dem es gelungen ist, bei schwangeren Kaninchen durch Impfung Tuberkulose zu erzeugen, ergaben gleichzeitig, dass in keinem einzigen Falle die unmittelbar darauf geborenen Nachkommen solcher Kaninchen tuberkulös waren u. s. W."

Ich habe derartige Untersuchungen niemals ausgeführt. Wohl aber habe ich in einer kurzen Mittheilung im Centralblatt für Gynäkologie 1884, S. 762 (Ueber die intrauterine Uebertragbarkeit des Erysipels) die Untersuchungen von Robert $\mathrm{Koch}$ über fötale $\mathrm{Tu}$ berkulose mit genauer Angabe der Quelle (Mittheilungen aus dem Kaiserl. Gesundheitsamte 1884, Bd. II, S. 86) citirt. Dieses Citat hat v. Ott offenbar für eine Originalmittheilung gehalten, ein Irrthum, vor welchem ein Zurückgehen auf die von mir eitirte Quelle Herrn v. Ott hätte schützen können.

Dorpat, 15. November 1885.

\section{Max Runge.}

Im ersten Hefte dieses Bandes, Seite 161, Zeile 2 von unten, muss es

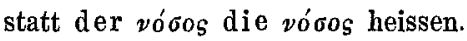

